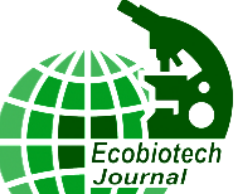 Nive \\ ТЕСТИРОВАНИЕ СЕЛЕКТИВНЫХ АГЕНТОВ ДЛЯ ОЦЕНКИ ЯРОВОЙ МЯГКОЙ ПШЕНИЦЫ НА УСТОЙЧИВОСТЬ К ЗАСУХЕ Сельдимирова О.А.
}

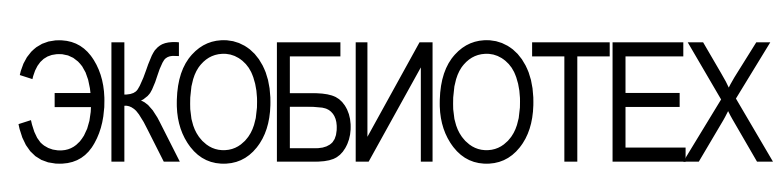

http://ecobiotech-journal.ru

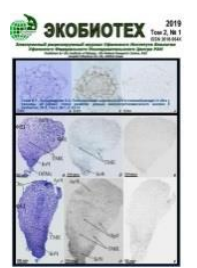

Уфимский Институт биологии Уфимского федерального исследовательского центра РАН, Уфа

E-mail: $\underline{\text { o_seldimirova@mail.ru }}$

Проанализировано влияние ряда концентраций маннита и ПЭГ-6000 на ростовые показатели и цитогистологический статус проростков изучаемых сортов яровой мягкой пшеницы. Установлено, что под влиянием имитантов засухи наиболее сильно изменяется такой ростовой показатель, как длина надземной части (колеоптиля или колеоптиля с появившимся из него первым листом), наименее сильно - число корней. На основании полученных данных для оценки на устойчивость к засухе рекомендуется использовать концентрацию ПЭГ 6000 в $12-14 \%$.

Ключевые слова: яровая мягкая пшеница, Triticum aestivum L., стресс, устойчивость к засухе, ПЭГ 6000, маннит

\section{TESTING OF SELECTIVE AGENTS FOR EVALUATION OF SPRING SOFT WHEAT FOR DROUGHT RESISTANCE Seldimirova O.A.}

Ufa Institute of Biology of the Ufa Federal Research Centre of the Russian Academy of Sciences, Ufa E-mail: o_seldimirova@mail.ru

The effect of number mannitol and PEG 6000 concentrations on the growth indicators and cytohistological status of seedlings of the studied spring wheat cultivars was analyzed. It has been established that under the influence of drought imitants, such a growth indicator as the length of the aerial part (coleoptile or coleoptile with the first leaf that emerged from it) changes most strongly, the number of roots - least strongly. Based on the obtained data, it is recommended to use a PEG 6000 in concentration $12-14 \%$ to assess drought reistance.

Keywords: spring soft wheat, Triticum aestivum L., stress, drought resistance, PEG 6000, mannitol

Поступила в редакиию: 8.02.2019

\section{DOI: $10.31163 / 2618-964 X-2019-2-1-51-62$}

\section{ВВЕДЕНИЕ}

Изменение климата - одна из глобальных проблем современности. С изменением климата в сельском хозяйстве напрямую связаны такие важные проблемы, как засуха и решение продовольственной безопасности. Засуха - длительный и значительный недостаток осадков, чаще при повышенной температуре и пониженной влажности воздуха, в результате которого иссякают запасы влаги в почве [Зыбалов, 2013; Кудоярова и др., 2013], что ведет к существенному снижению продуктивности или гибели урожая. Эта проблема актуальна и для Южного Урала - зоны рискованного земледелия.

Для выращиваемых сортов хлебных злаков, в том числе яровой мягкой пшеницы, обычно характерна относительно высокая устойчивость к неблагоприятным абиотическим факторам среды, включая засуху. Тем не менее, при отсутствии необходимой оценки селекционного материала засухоустойчивость новых сортов может оказаться недостаточной, поэтому оценка по данному показателю исходного материала и новых форм является необходимым условием эффективной селекции [Росеев и др., 2011]. Следует отметить, что важным звеном селекционного процесса должно стать тестирование полученных форм в лабораторных условиях, так как в благоприятные годы в полевых условиях выявить засухоустойчивые формы практически невозможно [Росеев и др., 2016]. К тому же, 
классические селекционно-генетические методы создания стрессоустойчивого материала, основанные на традиционных скрещиваниях, ограничены полигенным контролем признака и зачастую малоэффективны [Никитина и др., 2013].

Одним из перспективных подходов создания стрессоустойчивого материала является биотехнологический метод селекции in vitro, основанный на первоначальном отборе линий в культуре клеток in vitro [Гусева и др., 1990; Тучин, 2000; Терлецкая, 2008; Росеев и др., 2011, 2013; Никитина и др., 2013; Круглова и др., 2018]. Однако нерешенным остается ряд проблем, в том числе связанных с правильным выбором селективного агента и его адекватной концентрации [Дьячук, 2004; Круглова и др., 2018].

В качестве осмотического агента, моделирующего засуху, используют ряд веществ [обзор Круглова и др., 2018 и ссылки из него]: полиэтиленгликоль с молекулярной массой 6000 (ПЭГ 6000) или 10000 (ПЭГ 10000), маннит, сорбит, хлорид натрия. Однако все же наиболее часто в качестве имитантов засухи используются полиэтиленгликоль (ПЭГ 6000) и маннит. В литературе сообщается о достаточно широко варьирующих селективных концентрациях ПЭГ 6000 и маннита, используемых для оценки устойчивости злаков к засухе [обзор Круглова и др., 2018 и ссылки из него]. Сообщается, что сублетальные концентрации селективных агентов видоспецифичны [Аль-Холани, 2010], поэтому необходимо подбирать дозы селективных факторов для конкретного вида растений.

В связи с этим цель работы состояла в подборе селективного агента и его сублетальной концентрации для ряда сортов яровой мягкой пшеницы с перспективой дальнейшего использования в селекции in vitro.

\section{МАТЕРИАЛ И МЕТОДЫ}

Материалом для исследования послужили сорта яровой мягкой пшеница (Triticum aestivum L.) Архат, Ватан, Башкирская 28, Омская 36, Жница, которые характеризуются оригинаторами как засухоустойчивые и рассматриваются как перспективные для возделывания в климатической зоне Южного Урала, а также интенсивно используются в селекционных программах Башкирского научно-исследовательского института сельского хозяйства УФИЦ РАН (г. Уфа).

Для экспериментов использовали семена, любезно предоставленные И.П. Леонтьевым (ФГБУ «Государственная комиссия Российской Федерации по испытанию и охране селекционных достижений». Филиал по Республике Башкортостан).

В качестве селективных агентов использовали ПЭГ 6000 и маннит, наиболее часто применяемые в качестве имитантов засухи.

Для оценки влияния различных концентраций селективных агентов на ростовые показатели проростков и выявления сублетальной концентрации семена изучаемых сортов проращивали согласно ГОСТ 12038-84 на растворах маннита и ПЭГ 6000 в концентрациях 2$20 \%$, с шагом в $2 \%$. Контролем служило проращивание семян в дистиллированной воде.

Приготовление постоянных препаратов для проведения цито-гистологических исследований проводили согласно общепринятым методам, модифицированным применительно к биотехнологическим исследованиям [Круглова и др., 2013]. 
Статистическую обработку полученных результатов вели с применением программы Microsoft Office Excel 2010, учитывая основные статистические параметры. В таблицах представлены средние арифметические значения и ошибки средних.

\section{РЕЗУЛЬТАТЫ И ОБСУЖДЕНИЕ}

На первом этапе работы анализировали влияние концентраций селективных агентов на ростовые показатели проростков изучаемых сортов яровой мягкой пшеницы. Полученные данные отражены в таблицах 1-5.

Экспериментально установлено, что для всех изученных сортов значительное снижение показателей энергии прорастания и всхожести наблюдалось, начиная с концентрации ПЭГ 6000 в 12\%, однако минимального значения эти показатели достигали при концентрации ПЭГ 6000 в 14\%. Концентрация ПЭГ 6000 в 16\% была летальной, т.к. в этом случае не было отмечено каких-либо признаков прорастания. Таким образом, концентрация ПЭГ 6000 в 14\% являлась сублетальной. На рис. 1. отражены результаты по проращиванию проростков на дистиллированной воде (контроль), летальной и сублетальной концентрациях ПЭГ 6000 на примере пшеницы сорта Жница.

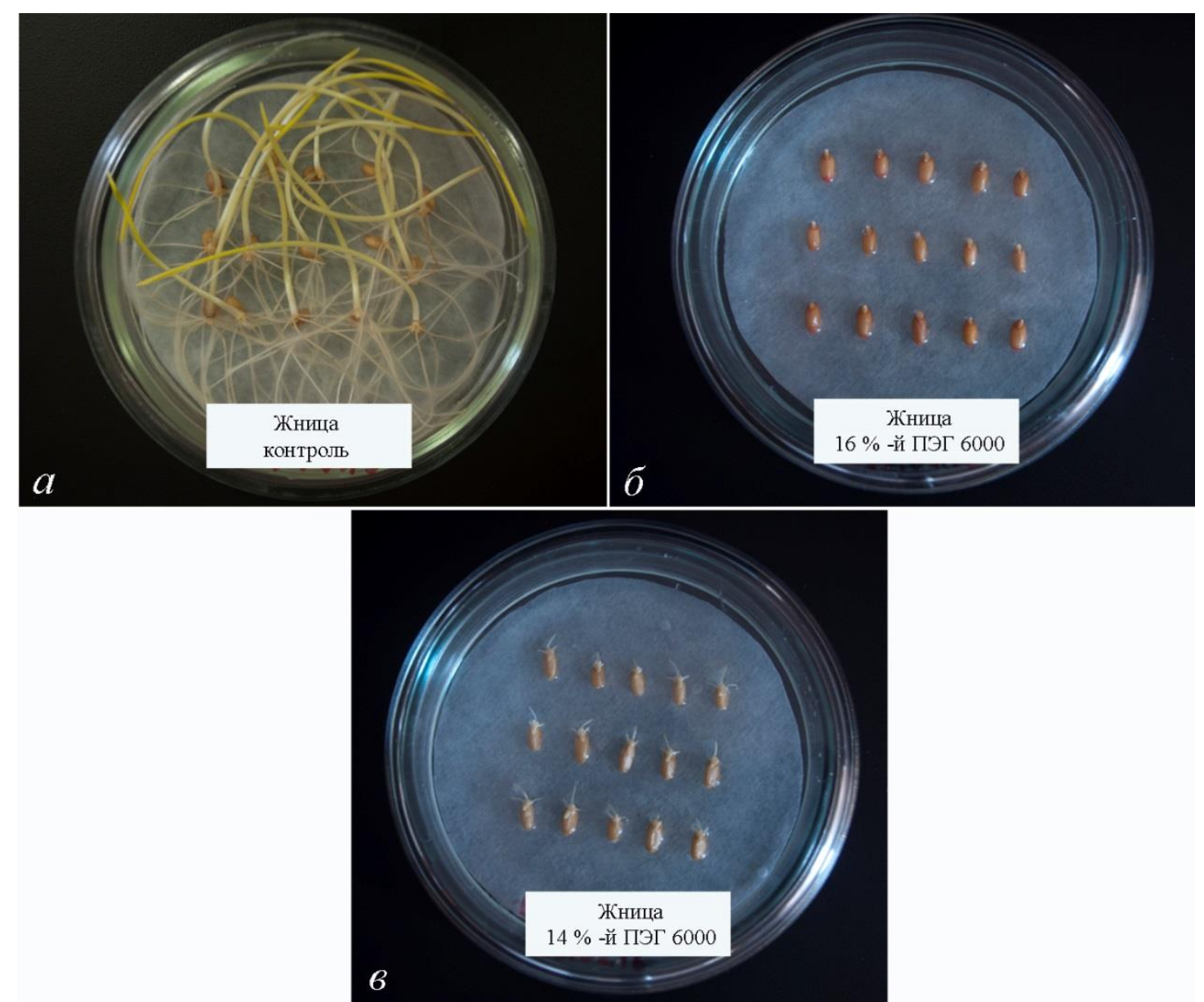

Рис. 1. Проростки пшеницы сорта Жница на 7-е сутки проращивания на дистиллированной воде (контроль, $a), 16 \%$-м (летальная концентрация, б) и 14\%-м (сублетальная концентрация, в) растворах ПЭГ 6000 
Таблица 1. Влияние концентрации селективных агентов на ростовые показатели проростков яровой мягкой пшеницы сорта Архат

\begin{tabular}{|c|c|c|c|c|c|c|c|c|c|c|c|c|c|c|c|}
\hline \multirow{3}{*}{ Показатели } & \multirow{3}{*}{ Контроль } & \multicolumn{14}{|c|}{ Концентрация селективного агента, \% } \\
\hline & & \multicolumn{2}{|r|}{2} & \multicolumn{2}{|c|}{4} & \multicolumn{2}{|c|}{6} & \multicolumn{2}{|r|}{8} & \multicolumn{2}{|c|}{10} & \multicolumn{2}{|c|}{12} & \multicolumn{2}{|c|}{14} \\
\hline & & $\begin{array}{l}\text { ПЭГ } \\
6000\end{array}$ & маннит & $\begin{array}{l}\text { ПЭГ } \\
6000\end{array}$ & маннит & $\begin{array}{l}\text { ПЭГ } \\
6000\end{array}$ & маннит & $\begin{array}{l}\text { ПЭГ } \\
6000\end{array}$ & маннит & $\begin{array}{l}\text { ПЭГ } \\
6000\end{array}$ & маннит & $\begin{array}{l}\text { ПЭГ } \\
6000\end{array}$ & маннит & $\begin{array}{l}\text { ПЭГ } \\
6000\end{array}$ & маннит \\
\hline $\begin{array}{l}\text { энергия } \\
\text { прорастания, } \\
\%\end{array}$ & $\begin{array}{l}99.4 \\
\pm \\
0.1\end{array}$ & $\begin{array}{l}98.3 \\
\pm \\
1.4\end{array}$ & $\begin{array}{c}95.6 \\
\pm \\
1.4\end{array}$ & $\begin{array}{l}85.2 \\
\pm \\
2.1\end{array}$ & $\begin{array}{l}77.8 \\
\pm \\
1.7\end{array}$ & $\begin{array}{l}83.5 \\
\pm \\
4.2\end{array}$ & $\begin{array}{l}59.4 \\
\pm \\
2.3\end{array}$ & $\begin{array}{c}80.6 \\
\pm \\
0.4\end{array}$ & $\begin{array}{l}31.8 \\
\pm \\
1.4\end{array}$ & $\begin{array}{c}79.5 \\
\pm \\
0.4\end{array}$ & $\begin{array}{l}10.6 \\
\pm \\
1.4\end{array}$ & $\begin{array}{c}63.2 \\
\pm \\
4.2\end{array}$ & - & $\begin{array}{c}8.2 \\
\pm \\
0.7\end{array}$ & - \\
\hline $\begin{array}{l}\text { всхожесть, } \\
\%\end{array}$ & $\begin{array}{c}99.8 \\
\pm \\
0.2 \\
\end{array}$ & $\begin{array}{c}98.6 \\
\pm \\
1.3 \\
\end{array}$ & $\begin{array}{c}91.2 \\
\pm \\
0.7 \\
\end{array}$ & $\begin{array}{c}98.3 \\
\pm \\
2.1 \\
\end{array}$ & $\begin{array}{c}81.2 \\
\pm \\
0.7 \\
\end{array}$ & $\begin{array}{c}97.4 \\
\pm \\
1.4 \\
\end{array}$ & $\begin{array}{c}56.2 \\
\pm \\
2.4 \\
\end{array}$ & $\begin{array}{c}93.9 \\
\pm \\
0.7 \\
\end{array}$ & $\begin{array}{c}45.3 \\
\pm \\
0.4\end{array}$ & $\begin{array}{c}90.3 \\
\pm \\
1.4 \\
\end{array}$ & - & $\begin{array}{c}75.6 \\
\pm \\
3.6\end{array}$ & - & $\begin{array}{c}43.5 \\
\pm \\
2.7 \\
\end{array}$ & - \\
\hline $\begin{array}{l}\text { длина } \\
\text { надземной } \\
\text { части, мм }\end{array}$ & $\begin{array}{c}14.5 \\
\pm \\
0.2 \\
\end{array}$ & $\begin{array}{c}12.3 \\
\pm \\
0.4 \\
\end{array}$ & $\begin{array}{c}11.3 \\
\pm \\
0.4 \\
\end{array}$ & $\begin{array}{c}11.4 \\
\pm \\
1.2 \\
\end{array}$ & $\begin{array}{c}8.6 \\
\pm \\
0.7\end{array}$ & $\begin{array}{c}9.3 \\
\pm \\
1.7 \\
\end{array}$ & $\begin{array}{c}6.4 \\
\pm \\
0.3\end{array}$ & $\begin{array}{c}5.1 \\
\pm \\
0.4 \\
\end{array}$ & $\begin{array}{c}1.5 \\
\pm \\
0.4\end{array}$ & $\begin{array}{c}4.2 \\
\pm \\
0.1 \\
\end{array}$ & - & $\begin{array}{c}3.9 \\
\pm \\
0.5\end{array}$ & - & $\begin{array}{c}1.7 \\
\pm \\
0.3 \\
\end{array}$ & - \\
\hline $\begin{array}{l}\text { длина } \\
\text { корней, } \\
\text { мм }\end{array}$ & $\begin{array}{c}13.0 \\
\pm \\
1.2 \\
\end{array}$ & $\begin{array}{c}12.8 \\
\pm \\
0.7 \\
\end{array}$ & $\begin{array}{c}11.3 \\
\pm \\
0.7\end{array}$ & $\begin{array}{c}10.7 \\
\pm \\
0.2 \\
\end{array}$ & $\begin{array}{c}7.6 \\
\pm \\
0.4\end{array}$ & $\begin{array}{c}10.2 \\
\pm \\
0.4 \\
\end{array}$ & $\begin{array}{c}5.2 \\
\pm \\
0.7 \\
\end{array}$ & $\begin{array}{c}6.8 \\
\pm \\
1.4 \\
\end{array}$ & $\begin{array}{c}2.4 \\
\pm \\
0.7\end{array}$ & $\begin{array}{c}4.6 \\
\pm \\
0.7 \\
\end{array}$ & - & $\begin{array}{c}3.9 \\
\pm \\
0.1\end{array}$ & - & $\begin{array}{c}3.3 \\
\pm \\
0.1 \\
\end{array}$ & - \\
\hline $\begin{array}{l}\text { число } \\
\text { корней, шт. }\end{array}$ & $\begin{array}{c}5.8 \\
\pm \\
0.2 \\
\end{array}$ & $\begin{array}{c}5.7 \\
\pm \\
0.3 \\
\end{array}$ & $\begin{array}{c}5.5 \\
\pm \\
0.4 \\
\end{array}$ & $\begin{array}{c}5.5 \\
\pm \\
0.4 \\
\end{array}$ & $\begin{array}{c}5.3 \\
\pm \\
1.4 \\
\end{array}$ & $\begin{array}{c}5.2 \\
\pm \\
1.2 \\
\end{array}$ & $\begin{array}{c}5.0 \\
\pm \\
0.1\end{array}$ & $\begin{array}{c}4.6 \\
\pm \\
0.2 \\
\end{array}$ & $\begin{array}{c}3.7 \\
\pm \\
0.4\end{array}$ & $\begin{array}{c}4.4 \\
\pm \\
0.3 \\
\end{array}$ & - & $\begin{array}{c}4.2 \\
\pm \\
0.7\end{array}$ & - & $\begin{array}{c}4.1 \\
\pm \\
0.2 \\
\end{array}$ & - \\
\hline $\begin{array}{l}\text { сырая масса } \\
\text { проростков, } \\
\text { мг }\end{array}$ & $\begin{array}{c}151.1 \\
\pm \\
6.1 \\
\end{array}$ & $\begin{array}{c}140.2 \\
\pm \\
5.2 \\
\end{array}$ & $\begin{array}{c}125.5 \\
\pm \\
5.8 \\
\end{array}$ & $\begin{array}{c}108.3 \\
\pm \\
3.2\end{array}$ & $\begin{array}{c}103.2 \\
\pm \\
4.1 \\
\end{array}$ & $\begin{array}{c}104.6 \\
\pm \\
4.7\end{array}$ & $\begin{array}{c}49.7 \\
\pm \\
1.7\end{array}$ & $\begin{array}{c}91.6 \\
\pm \\
2.1\end{array}$ & $\begin{array}{c}25.1 \\
\pm \\
1.7\end{array}$ & $\begin{array}{c}82.4 \\
\pm \\
2.7\end{array}$ & - & $\begin{array}{l}60.1 \\
\pm \\
1.4\end{array}$ & - & $\begin{array}{c}37.9 \\
\pm \\
5.1\end{array}$ & - \\
\hline $\begin{array}{l}\text { сухая масса } \\
\text { проростков, } \\
\text { мг }\end{array}$ & $\begin{array}{c}19.1 \\
\pm \\
1.2\end{array}$ & $\begin{array}{c}17.3 \\
\pm \\
1.7\end{array}$ & $\begin{array}{c}15.3 \\
\pm \\
1.7\end{array}$ & $\begin{array}{c}16.3 \\
\pm \\
2.1 \\
\end{array}$ & $\begin{array}{l}15.0 \\
\pm \\
1.4 \\
\end{array}$ & $\begin{array}{c}16.2 \\
\pm \\
1.4 \\
\end{array}$ & $\begin{array}{c}8.5 \\
\pm \\
1.7\end{array}$ & $\begin{array}{c}14.4 \\
\pm \\
2.1\end{array}$ & $\begin{array}{c}3.6 \\
\pm \\
0.5\end{array}$ & $\begin{array}{c}12.7 \\
\pm \\
0.3\end{array}$ & - & $\begin{array}{c}11.1 \\
\pm \\
0.4\end{array}$ & - & $\begin{array}{c}9.0 \\
\pm \\
1.7\end{array}$ & - \\
\hline
\end{tabular}

Примечание: здесь и далее цветом выделены минимальные значения ростовых показателей для обоих селективных агентов 
Таблица 2. Влияние концентрации селективных агентов на ростовые показатели

проростков яровой мягкой пшеницы сорта Ватан

\begin{tabular}{|c|c|c|c|c|c|c|c|c|c|c|c|c|c|c|c|}
\hline \multirow{3}{*}{ Показатели } & \multirow{3}{*}{ Контроль } & \multicolumn{14}{|c|}{ Концентрация селективного агента, \% } \\
\hline & & \multicolumn{2}{|r|}{2} & \multicolumn{2}{|c|}{4} & \multicolumn{2}{|c|}{6} & \multicolumn{2}{|c|}{8} & \multicolumn{2}{|c|}{10} & \multicolumn{2}{|c|}{12} & \multicolumn{2}{|c|}{14} \\
\hline & & $\begin{array}{l}\text { ПЭГ } \\
6000\end{array}$ & маннит & $\begin{array}{l}\text { ПЭГ } \\
6000\end{array}$ & маннит & $\begin{array}{l}\text { ПЭГ } \\
6000\end{array}$ & маннит & $\begin{array}{l}\text { ПЭГ } \\
6000\end{array}$ & маннит & $\begin{array}{l}\text { ПЭГ } \\
6000\end{array}$ & маннит & $\begin{array}{l}\text { ПЭГ } \\
6000\end{array}$ & маннит & $\begin{array}{l}\text { ПЭГ } \\
6000\end{array}$ & маннит \\
\hline $\begin{array}{l}\text { энергия } \\
\text { прорастания, } \\
\%\end{array}$ & $\begin{array}{c}99.4 \\
\pm \\
0.2\end{array}$ & $\begin{array}{c}96.3 \\
\pm \\
1.1\end{array}$ & $\begin{array}{c}93.1 \\
\pm \\
1.4\end{array}$ & $\begin{array}{c}82.2 \\
\pm \\
2.8\end{array}$ & $\begin{array}{c}76.2 \\
\pm \\
1.5\end{array}$ & $\begin{array}{c}82.1 \\
\pm \\
3.3\end{array}$ & $\begin{array}{c}54.3 \\
\pm \\
2.5\end{array}$ & $\begin{array}{c}79.9 \\
\pm \\
0.4\end{array}$ & $\begin{array}{c}29.8 \\
\pm \\
1.4\end{array}$ & $\begin{array}{c}77.3 \\
\pm \\
0.4\end{array}$ & - & $\begin{array}{c}55.4 \\
\pm \\
4.8\end{array}$ & - & $\begin{array}{c}5.2 \\
\pm \\
0.3\end{array}$ & - \\
\hline $\begin{array}{l}\text { всхожесть, } \\
\%\end{array}$ & $\begin{array}{c}99.7 \\
\pm \\
0.1\end{array}$ & $\begin{array}{c}96.5 \\
\pm \\
1.3 \\
\end{array}$ & $\begin{array}{c}88.5 \\
\pm \\
0.7 \\
\end{array}$ & $\begin{array}{c}95.4 \\
\pm \\
2.2 \\
\end{array}$ & $\begin{array}{c}75.6 \\
\pm \\
2.5 \\
\end{array}$ & $\begin{array}{c}94.4 \\
\pm \\
1.4 \\
\end{array}$ & $\begin{array}{c}44.3 \\
\pm \\
2.0\end{array}$ & $\begin{array}{c}92.1 \\
\pm \\
0.8 \\
\end{array}$ & $\begin{array}{c}33.1 \\
\pm \\
0.2 \\
\end{array}$ & $\begin{array}{c}90.4 \\
\pm \\
1.7 \\
\end{array}$ & - & $\begin{array}{c}68.2 \\
\pm \\
4.9 \\
\end{array}$ & - & $\begin{array}{c}42.6 \\
\pm \\
2.5 \\
\end{array}$ & - \\
\hline $\begin{array}{l}\text { длина } \\
\text { надземной } \\
\text { части, мм }\end{array}$ & $\begin{array}{c}13.4 \\
\pm \\
0.4 \\
\end{array}$ & $\begin{array}{c}9.3 \\
\pm \\
0.4 \\
\end{array}$ & $\begin{array}{c}7.2 \\
\pm \\
0.5 \\
\end{array}$ & $\begin{array}{c}6.5 \\
\pm \\
1.7 \\
\end{array}$ & $\begin{array}{c}5.4 \\
\pm \\
1.7 \\
\end{array}$ & $\begin{array}{c}5.5 \\
\pm \\
2.4 \\
\end{array}$ & $\begin{array}{c}4.3 \\
\pm \\
0.7\end{array}$ & $\begin{array}{c}3.1 \\
\pm \\
0.2 \\
\end{array}$ & $\begin{array}{c}0.7 \\
\pm \\
0.1 \\
\end{array}$ & $\begin{array}{c}2.7 \\
\pm \\
0.2 \\
\end{array}$ & - & $\begin{array}{c}2.1 \\
\pm \\
0.4 \\
\end{array}$ & - & $\begin{array}{c}1.5 \\
\pm \\
0.1 \\
\end{array}$ & - \\
\hline $\begin{array}{l}\text { длина } \\
\text { корней, } \\
\text { мм }\end{array}$ & $\begin{array}{c}12.8 \\
\pm \\
1.4\end{array}$ & $\begin{array}{c}11.6 \\
\pm \\
0.5\end{array}$ & $\begin{array}{c}9.2 \\
\pm \\
1.4\end{array}$ & $\begin{array}{l}8.4 \\
\pm \\
1.4\end{array}$ & $\begin{array}{c}5.5 \\
\pm \\
0.7\end{array}$ & $\begin{array}{c}8.1 \\
\pm \\
0.4\end{array}$ & $\begin{array}{c}3.6 \\
\pm \\
1.2\end{array}$ & $\begin{array}{c}4.9 \\
\pm \\
0.5\end{array}$ & $\begin{array}{c}1.1 \\
\pm \\
0.1\end{array}$ & $\begin{array}{c}2.5 \\
\pm \\
0.1\end{array}$ & - & $\begin{array}{c}2.2 \\
\pm \\
0.2\end{array}$ & - & $\begin{array}{c}1.7 \\
\pm \\
0.1\end{array}$ & - \\
\hline $\begin{array}{l}\text { число } \\
\text { корней, шт. }\end{array}$ & $\begin{array}{c}5.5 \\
\pm \\
1.2\end{array}$ & $\begin{array}{c}5.4 \\
\pm \\
0.2\end{array}$ & $\begin{array}{c}5.2 \\
\pm \\
0.2\end{array}$ & $\begin{array}{l}5.2 \\
\pm \\
1.4\end{array}$ & $\begin{array}{c}4.9 \\
\pm \\
0.3\end{array}$ & $\begin{array}{c}5.1 \\
\pm \\
0.2\end{array}$ & $\begin{array}{c}4.8 \\
\pm \\
0.3\end{array}$ & $\begin{array}{c}4.3 \\
\pm \\
0.3\end{array}$ & $\begin{array}{c}3.4 \\
\pm \\
0.1\end{array}$ & $\begin{array}{c}4.1 \\
\pm \\
0.3\end{array}$ & - & $\begin{array}{c}3.9 \\
\pm \\
0.5\end{array}$ & - & $\begin{array}{c}3.8 \\
\pm \\
0.1\end{array}$ & - \\
\hline $\begin{array}{l}\text { сырая масса } \\
\text { проростков, } \\
\text { мГ }\end{array}$ & $\begin{array}{c}128.3 \\
\pm \\
3.2\end{array}$ & $\begin{array}{c}125.4 \\
\pm \\
1.4\end{array}$ & $\begin{array}{c}118.2 \\
\pm \\
2.7\end{array}$ & $\begin{array}{c}98.4 \\
\pm \\
4.2\end{array}$ & $\begin{array}{c}96.6 \\
\pm \\
4.5\end{array}$ & $\begin{array}{c}97.4 \\
\pm \\
5.1\end{array}$ & $\begin{array}{c}41.2 \\
\pm \\
2.7\end{array}$ & $\begin{array}{c}85.3 \\
\pm \\
3.2\end{array}$ & $\begin{array}{c}21.6 \\
\pm \\
1.3\end{array}$ & $\begin{array}{c}74.7 \\
\pm \\
1.4\end{array}$ & - & $\begin{array}{c}53.2 \\
\pm \\
2.1\end{array}$ & - & $\begin{array}{c}30.8 \\
\pm \\
2.7\end{array}$ & - \\
\hline $\begin{array}{l}\text { сухая масса } \\
\text { проростков, } \\
\text { мГ }\end{array}$ & $\begin{array}{c}16.8 \\
\pm \\
1.4\end{array}$ & $\begin{array}{c}15.2 \\
\pm \\
0.4\end{array}$ & $\begin{array}{c}13.6 \\
\pm \\
1.2\end{array}$ & $\begin{array}{c}14.4 \\
\pm \\
0.8\end{array}$ & $\begin{array}{c}13.2 \\
\pm \\
1.4\end{array}$ & $\begin{array}{c}14.3 \\
\pm \\
1.4\end{array}$ & $\begin{array}{c}6.8 \\
\pm \\
0.4\end{array}$ & $\begin{array}{c}12.4 \\
\pm \\
1.7\end{array}$ & $\begin{array}{c}1.9 \\
\pm \\
0.4\end{array}$ & $\begin{array}{c}10.7 \\
\pm \\
0.4\end{array}$ & - & $\begin{array}{c}9.6 \\
\pm \\
0.2\end{array}$ & - & $\begin{array}{c}6.5 \\
\pm \\
1.2\end{array}$ & - \\
\hline
\end{tabular}


Таблица 3. Влияние концентрации селективных агентов на ростовые показатели

проростков яровой мягкой пшеницы сорта Башкирская 28

\begin{tabular}{|c|c|c|c|c|c|c|c|c|c|c|c|c|c|c|c|}
\hline \multirow{3}{*}{ Показатели } & \multirow{3}{*}{ Контроль } & \multicolumn{14}{|c|}{ Концентрация селективного агента, \% } \\
\hline & & \multicolumn{2}{|c|}{2} & \multicolumn{2}{|c|}{4} & \multicolumn{2}{|c|}{6} & \multicolumn{2}{|c|}{8} & \multicolumn{2}{|c|}{10} & \multicolumn{2}{|c|}{12} & \multicolumn{2}{|c|}{14} \\
\hline & & $\begin{array}{l}\text { ПЭГ } \\
6000\end{array}$ & маннит & $\begin{array}{l}\text { ПЭГ } \\
6000\end{array}$ & маннит & $\begin{array}{l}\text { ПЭГ } \\
6000\end{array}$ & маннит & $\begin{array}{l}\text { ПЭГ } \\
6000\end{array}$ & маннит & $\begin{array}{l}\text { ПЭГ } \\
6000\end{array}$ & маннит & $\begin{array}{l}\text { ПЭГ } \\
6000\end{array}$ & маннит & $\begin{array}{l}\text { ПЭГ } \\
6000\end{array}$ & маннит \\
\hline энергия & 99.2 & 98.4 & 95.2 & 84.3 & 78.2 & 84.3 & 58.6 & 82.4 & 32.7 & 81.3 & 12.3 & 67.2 & & 7.5 & \\
\hline $\begin{array}{l}\text { прорастания, } \\
\%\end{array}$ & $\begin{array}{c} \pm \\
0.7\end{array}$ & $\begin{array}{c} \pm \\
1.2\end{array}$ & $\begin{array}{c} \pm \\
1.3\end{array}$ & $\begin{array}{c} \pm \\
2.5\end{array}$ & $\begin{array}{c} \pm \\
1.8\end{array}$ & $\begin{array}{c} \pm \\
3.7\end{array}$ & $\begin{array}{c} \pm \\
2.8\end{array}$ & $\begin{array}{c} \pm \\
0.3\end{array}$ & $\begin{array}{c} \pm \\
1.7\end{array}$ & $\begin{array}{c} \pm \\
0.7\end{array}$ & $\begin{array}{c} \pm \\
1.2\end{array}$ & $\begin{array}{c} \pm \\
5.4\end{array}$ & - & $\begin{array}{c} \pm \\
0.6\end{array}$ & - \\
\hline $\begin{array}{l}\text { всхожесть, } \\
\%\end{array}$ & $\begin{array}{c}99.5 \\
\pm \\
0.2\end{array}$ & $\begin{array}{c}98.7 \\
\pm \\
1.4 \\
\end{array}$ & $\begin{array}{c}90.5 \\
\pm \\
0.9\end{array}$ & $\begin{array}{c}97.6 \\
\pm \\
2.4 \\
\end{array}$ & $\begin{array}{c}77.2 \\
\pm \\
2.4\end{array}$ & $\begin{array}{c}96.5 \\
\pm \\
1.7 \\
\end{array}$ & $\begin{array}{c}46.5 \\
\pm \\
2.9\end{array}$ & $\begin{array}{c}94.2 \\
\pm \\
0.7\end{array}$ & $\begin{array}{c}35.2 \\
\pm \\
0.1\end{array}$ & $\begin{array}{c}92.3 \\
\pm \\
1.4 \\
\end{array}$ & - & $\begin{array}{c}71.1 \\
\pm \\
5.8 \\
\end{array}$ & - & $\begin{array}{c}44.6 \\
\pm \\
2.2 \\
\end{array}$ & - \\
\hline $\begin{array}{l}\text { длина } \\
\text { надземной } \\
\text { части, мм }\end{array}$ & $\begin{array}{c}13.2 \\
\pm \\
0.7\end{array}$ & $\begin{array}{c}10.4 \\
\pm \\
0.7\end{array}$ & $\begin{array}{c}9.3 \\
\pm \\
0.5\end{array}$ & $\begin{array}{l}8.2 \\
\pm \\
1.4\end{array}$ & $\begin{array}{l}7.4 \\
\pm \\
1.7\end{array}$ & $\begin{array}{c}7.6 \\
\pm \\
2.6\end{array}$ & $\begin{array}{c}6.3 \\
\pm \\
0.6\end{array}$ & $\begin{array}{c}4.1 \\
\pm \\
0.3\end{array}$ & $\begin{array}{c}0.8 \\
\pm \\
0.1\end{array}$ & $\begin{array}{c}3.9 \\
\pm \\
0.2\end{array}$ & - & $\begin{array}{c}3.7 \\
\pm \\
0.7\end{array}$ & - & $\begin{array}{c}1.9 \\
\pm \\
0.2\end{array}$ & - \\
\hline $\begin{array}{l}\text { длина } \\
\text { корней, } \\
\text { мм }\end{array}$ & $\begin{array}{c}12.9 \\
\pm \\
1.2 \\
\end{array}$ & $\begin{array}{c}12.5 \\
\pm \\
0.7\end{array}$ & $\begin{array}{c}10.3 \\
\pm \\
1.2 \\
\end{array}$ & $\begin{array}{c}9.5 \\
\pm \\
0.4\end{array}$ & $\begin{array}{c}6.3 \\
\pm \\
0.4\end{array}$ & $\begin{array}{c}9.3 \\
\pm \\
0.5\end{array}$ & $\begin{array}{c}4.5 \\
\pm \\
1.3\end{array}$ & $\begin{array}{c}5.8 \\
\pm \\
0.4 \\
\end{array}$ & $\begin{array}{c}2.1 \\
\pm \\
0.2 \\
\end{array}$ & $\begin{array}{c}3.7 \\
\pm \\
0.2 \\
\end{array}$ & - & $\begin{array}{c}4.2 \\
\pm \\
0.3\end{array}$ & - & $\begin{array}{c}2.6 \\
\pm \\
0.3 \\
\end{array}$ & - \\
\hline $\begin{array}{l}\text { число } \\
\text { корней, шт. }\end{array}$ & $\begin{array}{c}5.7 \\
\pm \\
1.2\end{array}$ & $\begin{array}{c}5.6 \\
\pm \\
0.7\end{array}$ & $\begin{array}{c}5.4 \\
\pm \\
0.3\end{array}$ & $\begin{array}{c}5.4 \\
\pm \\
0.4\end{array}$ & $\begin{array}{c}5.2 \\
\pm \\
0.4\end{array}$ & $\begin{array}{c}5.1 \\
\pm \\
0.2\end{array}$ & $\begin{array}{c}4.9 \\
\pm \\
0.3\end{array}$ & $\begin{array}{c}4.5 \\
\pm \\
0.2\end{array}$ & $\begin{array}{c}3.6 \\
\pm \\
0.1\end{array}$ & $\begin{array}{c}4.3 \\
\pm \\
0.3\end{array}$ & - & $\begin{array}{c}4.1 \\
\pm \\
0.4\end{array}$ & - & $\begin{array}{c}3.9 \\
\pm \\
0.5\end{array}$ & - \\
\hline $\begin{array}{l}\text { сырая масса } \\
\text { проростков, } \\
\text { мГ }\end{array}$ & $\begin{array}{c}146.2 \\
\pm \\
3.1\end{array}$ & $\begin{array}{c}135.4 \\
\pm \\
2.7\end{array}$ & $\begin{array}{c}120.4 \\
\pm \\
3.4\end{array}$ & $\begin{array}{c}102.7 \\
\pm \\
5.1\end{array}$ & $\begin{array}{c}98.6 \\
\pm \\
4.7\end{array}$ & $\begin{array}{c}99.5 \\
\pm \\
5.2\end{array}$ & $\begin{array}{c}43.8 \\
\pm \\
2.6\end{array}$ & $\begin{array}{c}86.7 \\
\pm \\
3.4\end{array}$ & $\begin{array}{c}22.6 \\
\pm \\
1.2\end{array}$ & $\begin{array}{c}78.7 \\
\pm \\
3.4\end{array}$ & - & $\begin{array}{c}55.2 \\
\pm \\
3.1\end{array}$ & - & $\begin{array}{c}33.4 \\
\pm \\
3.4\end{array}$ & - \\
\hline $\begin{array}{l}\text { сухая масса } \\
\text { проростков, } \\
\text { мГ }\end{array}$ & $\begin{array}{c}18.2 \\
\pm \\
1.4\end{array}$ & $\begin{array}{c}16.3 \\
\pm \\
0.7\end{array}$ & $\begin{array}{c}14.5 \\
\pm \\
1.4\end{array}$ & $\begin{array}{c}15.4 \\
\pm \\
0.7\end{array}$ & $\begin{array}{c}14.1 \\
\pm \\
1.2\end{array}$ & $\begin{array}{c}15.2 \\
\pm \\
1.2\end{array}$ & $\begin{array}{c}7.7 \\
\pm \\
1.4\end{array}$ & $\begin{array}{c}13.5 \\
\pm \\
2.2\end{array}$ & $\begin{array}{c}2.7 \\
\pm \\
0.7\end{array}$ & $\begin{array}{c}11.8 \\
\pm \\
0.5\end{array}$ & - & $\begin{array}{c}10.4 \\
\pm \\
0.3\end{array}$ & - & $\begin{array}{c}8.3 \\
\pm \\
0.7\end{array}$ & - \\
\hline
\end{tabular}


Таблица 4. Влияние концентрации селективных агентов на ростовые показатели

проростков яровой мягкой пшеницы сорта Омская 36

\begin{tabular}{|c|c|c|c|c|c|c|c|c|c|c|c|c|c|c|c|}
\hline \multirow{3}{*}{ Показатели } & \multirow{3}{*}{ Контроль } & \multicolumn{14}{|c|}{ Концентрация селективного агента, \% } \\
\hline & & \multicolumn{2}{|c|}{2} & \multicolumn{2}{|c|}{4} & \multicolumn{2}{|r|}{6} & \multicolumn{2}{|r|}{8} & \multicolumn{2}{|c|}{10} & \multicolumn{2}{|c|}{12} & \multicolumn{2}{|c|}{14} \\
\hline & & $\begin{array}{l}\text { ПЭГ } \\
6000\end{array}$ & маннит & $\begin{array}{l}\text { ПЭГ } \\
6000\end{array}$ & маннит & $\begin{array}{l}\text { ПЭГ } \\
6000\end{array}$ & маннит & $\begin{array}{l}\text { ПЭГ } \\
6000\end{array}$ & маннит & $\begin{array}{l}\text { ПЭГ } \\
6000\end{array}$ & маннит & $\begin{array}{l}\text { ПЭГ } \\
6000\end{array}$ & маннит & $\begin{array}{l}\text { ПЭГ } \\
6000\end{array}$ & маннит \\
\hline $\begin{array}{l}\text { энергия } \\
\text { прорастания, } \\
\%\end{array}$ & $\begin{array}{c}99.3 \\
\pm \\
0.2\end{array}$ & $\begin{array}{c}99.4 \\
\pm \\
0.2\end{array}$ & $\begin{array}{l}96.1 \\
\pm \\
1.4\end{array}$ & $\begin{array}{c}89.5 \\
\pm \\
2.3\end{array}$ & $\begin{array}{l}81.3 \\
\pm \\
1.7\end{array}$ & $\begin{array}{c}86.7 \\
\pm \\
1.7\end{array}$ & $\begin{array}{c}60.2 \\
\pm \\
3.2\end{array}$ & $\begin{array}{c}83.1 \\
\pm \\
1.4\end{array}$ & $\begin{array}{c}40.6 \\
\pm \\
1.4\end{array}$ & $\begin{array}{c}81.9 \\
\pm \\
0.9\end{array}$ & $\begin{array}{l}11.5 \\
\pm \\
1.7\end{array}$ & $\begin{array}{c}65.3 \\
\pm \\
4.2\end{array}$ & - & $\begin{array}{c}10.6 \\
\pm \\
1.2\end{array}$ & - \\
\hline $\begin{array}{l}\text { всхожесть, } \\
\%\end{array}$ & $\begin{array}{l}99.6 \\
\pm \\
0.2\end{array}$ & $\begin{array}{c}98.5 \\
\pm \\
1.2\end{array}$ & $\begin{array}{c}91.2 \\
\pm \\
0.7\end{array}$ & $\begin{array}{c}96.4 \\
\pm \\
0.7\end{array}$ & $\begin{array}{c}79.1 \\
\pm \\
2.1\end{array}$ & $\begin{array}{c}95.3 \\
\pm \\
2.4\end{array}$ & $\begin{array}{c}44.2 \\
\pm \\
1.7\end{array}$ & $\begin{array}{c}94.1 \\
\pm \\
0.4\end{array}$ & $\begin{array}{c}37.3 \\
\pm \\
0.1\end{array}$ & $\begin{array}{c}90.6 \\
\pm \\
3.5\end{array}$ & - & $\begin{array}{c}70.8 \\
\pm \\
2.7\end{array}$ & - & $\begin{array}{l}43.2 \\
\pm \\
2.1\end{array}$ & - \\
\hline $\begin{array}{l}\text { длина } \\
\text { надземной } \\
\text { части, мм }\end{array}$ & $\begin{array}{c}14.6 \\
\pm \\
0.7\end{array}$ & $\begin{array}{c}11.2 \\
\pm \\
0.7 \\
\end{array}$ & $\begin{array}{c}10.4 \\
\pm \\
0.5 \\
\end{array}$ & $\begin{array}{c}9.1 \\
\pm \\
0.3\end{array}$ & $\begin{array}{c}8.3 \\
\pm \\
0.4\end{array}$ & $\begin{array}{c}8.5 \\
\pm \\
2.1\end{array}$ & $\begin{array}{c}7.1 \\
\pm \\
0.3 \\
\end{array}$ & $\begin{array}{c}5.4 \\
\pm \\
0.3 \\
\end{array}$ & $\begin{array}{c}0.6 \\
\pm \\
0.2 \\
\end{array}$ & $\begin{array}{c}3.7 \\
\pm \\
0.1 \\
\end{array}$ & - & $\begin{array}{c}3.2 \\
\pm \\
0.4\end{array}$ & - & $\begin{array}{c}1.6 \\
\pm \\
0.2\end{array}$ & - \\
\hline $\begin{array}{l}\text { длина } \\
\text { корней, } \\
\text { мм }\end{array}$ & $\begin{array}{c}12.4 \\
\pm \\
2.1\end{array}$ & $\begin{array}{c}12.0 \\
\pm \\
1.7\end{array}$ & $\begin{array}{c}9.8 \\
\pm \\
1.4\end{array}$ & $\begin{array}{c}9.1 \\
\pm \\
1.4\end{array}$ & $\begin{array}{c}5.8 \\
\pm \\
0.2\end{array}$ & $\begin{array}{c}8.8 \\
\pm \\
1.2\end{array}$ & $\begin{array}{c}4.1 \\
\pm \\
0.7\end{array}$ & $\begin{array}{c}5.3 \\
\pm \\
0.4\end{array}$ & $\begin{array}{c}1.6 \\
\pm \\
0.4\end{array}$ & $\begin{array}{c}3.2 \\
\pm \\
0.3\end{array}$ & - & $\begin{array}{c}2.9 \\
\pm \\
0.1\end{array}$ & - & $\begin{array}{c}1.8 \\
\pm \\
0.1\end{array}$ & - \\
\hline $\begin{array}{l}\text { число } \\
\text { корней, шт. }\end{array}$ & $\begin{array}{c}5.8 \\
\pm \\
1.1\end{array}$ & $\begin{array}{c}5.7 \\
\pm \\
0.3\end{array}$ & $\begin{array}{c}5.5 \\
\pm \\
0.3\end{array}$ & $\begin{array}{c}5.5 \\
\pm \\
1.4\end{array}$ & $\begin{array}{c}5.3 \\
\pm \\
1.2\end{array}$ & $\begin{array}{c}5.2 \\
\pm \\
0.7\end{array}$ & $\begin{array}{c}5.0 \\
\pm \\
0.3\end{array}$ & $\begin{array}{c}4.6 \\
\pm \\
0.2\end{array}$ & $\begin{array}{c}3.7 \\
\pm \\
0.2\end{array}$ & $\begin{array}{c}4.4 \\
\pm \\
0.3\end{array}$ & - & $\begin{array}{c}4.2 \\
\pm \\
0.7\end{array}$ & - & $\begin{array}{c}4.1 \\
\pm \\
1.2\end{array}$ & - \\
\hline $\begin{array}{l}\text { сырая масса } \\
\text { проростков, } \\
\text { мг }\end{array}$ & $\begin{array}{c}139.8 \\
\pm \\
5.8 \\
\end{array}$ & $\begin{array}{c}133.4 \\
\pm \\
7.2 \\
\end{array}$ & $\begin{array}{c}118.2 \\
\pm \\
4.4 \\
\end{array}$ & $\begin{array}{c}100.5 \\
\pm \\
2.4 \\
\end{array}$ & $\begin{array}{c}96.4 \\
\pm \\
2.1 \\
\end{array}$ & $\begin{array}{c}97.3 \\
\pm \\
3.3 \\
\end{array}$ & $\begin{array}{c}41.6 \\
\pm \\
1.7 \\
\end{array}$ & $\begin{array}{c}84.5 \\
\pm \\
3.2 \\
\end{array}$ & $\begin{array}{c}22.4 \\
\pm \\
1.7 \\
\end{array}$ & $\begin{array}{c}76.5 \\
\pm \\
4.8 \\
\end{array}$ & - & $\begin{array}{c}53.1 \\
\pm \\
0.7 \\
\end{array}$ & - & $\begin{array}{c}31.2 \\
\pm \\
1.2 \\
\end{array}$ & - \\
\hline $\begin{array}{l}\text { сухая масса } \\
\text { проростков, } \\
\text { мг }\end{array}$ & $\begin{array}{c}16.1 \\
\pm \\
1.2 \\
\end{array}$ & $\begin{array}{c}14.1 \\
\pm \\
0.4 \\
\end{array}$ & $\begin{array}{c}12.3 \\
\pm \\
1.7 \\
\end{array}$ & $\begin{array}{c}13.2 \\
\pm \\
0.7 \\
\end{array}$ & $\begin{array}{c}11.9 \\
\pm \\
0.7 \\
\end{array}$ & $\begin{array}{c}13.0 \\
\pm \\
2.1 \\
\end{array}$ & $\begin{array}{c}5.5 \\
\pm \\
1.7 \\
\end{array}$ & $\begin{array}{c}11.3 \\
\pm \\
3.3 \\
\end{array}$ & $\begin{array}{c}2.3 \\
\pm \\
0.2 \\
\end{array}$ & $\begin{array}{c}9.6 \\
\pm \\
1.4\end{array}$ & - & $\begin{array}{c}8.2 \\
\pm \\
0.3\end{array}$ & - & $\begin{array}{c}6.3 \\
\pm \\
0.4\end{array}$ & - \\
\hline
\end{tabular}


Таблица 5. Влияние концентрации селективных агентов на ростовые показатели проростков яровой мягкой пшеницы сорта Жница

\begin{tabular}{|c|c|c|c|c|c|c|c|c|c|c|c|c|c|c|c|}
\hline \multirow{3}{*}{ Показатели } & \multirow{3}{*}{ Контроль } & \multicolumn{14}{|c|}{ Концентрация селективного агента, \% } \\
\hline & & \multicolumn{2}{|c|}{2} & \multicolumn{2}{|c|}{4} & \multicolumn{2}{|c|}{6} & \multicolumn{2}{|r|}{8} & \multicolumn{2}{|c|}{10} & \multicolumn{2}{|c|}{12} & \multicolumn{2}{|c|}{14} \\
\hline & & $\begin{array}{l}\text { ПЭГ } \\
6000\end{array}$ & маннит & $\begin{array}{l}\text { ПЭГ } \\
6000\end{array}$ & маннит & $\begin{array}{l}\text { ПЭГ } \\
6000\end{array}$ & маннит & $\begin{array}{l}\text { ПЭГ } \\
6000\end{array}$ & маннит & $\begin{array}{l}\text { ПЭГ } \\
6000\end{array}$ & маннит & $\begin{array}{l}\text { ПЭГ } \\
6000\end{array}$ & маннит & $\begin{array}{l}\text { ПЭГ } \\
6000\end{array}$ & маннит \\
\hline $\begin{array}{c}\text { энергия } \\
\text { прорастания, } \\
\% \\
\end{array}$ & $\begin{array}{c}97.8 \\
\pm \\
2.7 \\
\end{array}$ & $\begin{array}{c}97.3 \\
\pm \\
1.7 \\
\end{array}$ & $\begin{array}{c}93.3 \\
\pm \\
1.2 \\
\end{array}$ & $\begin{array}{c}82.2 \\
\pm \\
2.7 \\
\end{array}$ & $\begin{array}{c}74.3 \\
\pm \\
2.8 \\
\end{array}$ & $\begin{array}{c}82.2 \\
\pm \\
2.7 \\
\end{array}$ & $\begin{array}{c}52.2 \\
\pm \\
12.7 \\
\end{array}$ & $\begin{array}{c}81.4 \\
\pm \\
0.3 \\
\end{array}$ & $\begin{array}{c}27.8 \\
\pm \\
2.7\end{array}$ & $\begin{array}{c}80.2 \\
\pm \\
0.4 \\
\end{array}$ & - & $\begin{array}{c}63.1 \\
\pm \\
7.6 \\
\end{array}$ & - & $\begin{array}{c}6.7 \\
\pm \\
0.1 \\
\end{array}$ & - \\
\hline $\begin{array}{c}\text { всхожесть, } \\
\%\end{array}$ & $\begin{array}{c}99.3 \\
\pm \\
0.9\end{array}$ & $\begin{array}{c}98.4 \\
\pm \\
1.5 \\
\end{array}$ & $\begin{array}{c}88.5 \\
\pm \\
1.7\end{array}$ & $\begin{array}{c}95.5 \\
\pm \\
2.7\end{array}$ & $\begin{array}{l}75.2 \\
\pm \\
2.3\end{array}$ & $\begin{array}{c}95.5 \\
\pm \\
2.7\end{array}$ & $\begin{array}{l}42.3 \\
\pm \\
3.4\end{array}$ & $\begin{array}{c}95.1 \\
\pm \\
0.4\end{array}$ & 33.6 & $\begin{array}{c}91.1 \\
\pm \\
2.7\end{array}$ & - & $\begin{array}{c}71.1 \\
\pm \\
5.8\end{array}$ & - & $\begin{array}{c}42.2 \\
\pm \\
2.7\end{array}$ & - \\
\hline $\begin{array}{c}\text { длина } \\
\text { надземной } \\
\text { части, мм }\end{array}$ & $\begin{array}{c}11.1 \\
\pm \\
0.5\end{array}$ & $\begin{array}{c}9.5 \\
\pm \\
0.5 \\
\end{array}$ & $\begin{array}{c}8.4 \\
\pm \\
0.3 \\
\end{array}$ & $\begin{array}{c}7.1 \\
\pm \\
0.5 \\
\end{array}$ & $\begin{array}{c}6.5 \\
\pm \\
0.8\end{array}$ & $\begin{array}{c}7.1 \\
\pm \\
2.6 \\
\end{array}$ & $\begin{array}{l}5.4 \\
\pm \\
1.6\end{array}$ & $\begin{array}{c}4.8 \\
\pm \\
0.3 \\
\end{array}$ & $\begin{array}{c}0.3 \\
\pm \\
0.1\end{array}$ & $\begin{array}{c}4.1 \\
\pm \\
0.2 \\
\end{array}$ & - & $\begin{array}{c}2.8 \\
\pm \\
0.2 \\
\end{array}$ & - & $\begin{array}{c}1.1 \\
\pm \\
0.1\end{array}$ & - \\
\hline $\begin{array}{c}\text { длина } \\
\text { корней, } \\
\text { мм }\end{array}$ & $\begin{array}{c}12.1 \\
\pm \\
0.5\end{array}$ & $\begin{array}{c}11.9 \\
\pm \\
0.4\end{array}$ & $\begin{array}{c}9.9 \\
\pm \\
1.2\end{array}$ & $\begin{array}{l}9.3 \\
\pm \\
0.5 \\
\end{array}$ & $\begin{array}{c}5.4 \\
\pm \\
0.3\end{array}$ & $\begin{array}{c}9.2 \\
\pm \\
0.5 \\
\end{array}$ & $\begin{array}{c}3.9 \\
\pm \\
0.3\end{array}$ & $\begin{array}{c}5.2 \\
\pm \\
0.3 \\
\end{array}$ & $\begin{array}{c}1.8 \\
\pm \\
0.2\end{array}$ & $\begin{array}{l}3.3 \\
\pm \\
0.2\end{array}$ & - & $\begin{array}{c}3.3 \\
\pm \\
0.3\end{array}$ & - & $\begin{array}{c}2.6 \\
\pm \\
0.3\end{array}$ & - \\
\hline $\begin{array}{c}\text { число } \\
\text { корней, шт. }\end{array}$ & $\begin{array}{c}5.4 \\
\pm \\
0.2\end{array}$ & $\begin{array}{c}5.1 \\
\pm \\
0.1\end{array}$ & $\begin{array}{c}5.2 \\
\pm \\
0.3\end{array}$ & $\begin{array}{l}4.9 \\
\pm \\
0.1\end{array}$ & $\begin{array}{c}5.1 \\
\pm \\
0.1\end{array}$ & $\begin{array}{c}4.7 \\
\pm \\
0.2\end{array}$ & $\begin{array}{c}4.9 \\
\pm \\
0.2\end{array}$ & $\begin{array}{l}4.3 \\
\pm \\
0.2\end{array}$ & $\begin{array}{c}2.6 \\
\pm \\
0.1\end{array}$ & $\begin{array}{l}4.3 \\
\pm \\
0.3\end{array}$ & - & $\begin{array}{c}4.2 \\
\pm \\
0.2\end{array}$ & - & $\begin{array}{c}4.0 \\
\pm \\
0.3\end{array}$ & - \\
\hline $\begin{array}{c}\text { сырая масса } \\
\text { проростков, } \\
\text { мг }\end{array}$ & $\begin{array}{c}136.6 \\
\pm \\
0.8 \\
\end{array}$ & $\begin{array}{c}120.4 \\
\pm \\
6.5 \\
\end{array}$ & $\begin{array}{c}115.9 \\
\pm \\
4.8 \\
\end{array}$ & $\begin{array}{c}92.8 \\
\pm \\
4.1 \\
\end{array}$ & $\begin{array}{c}88.7 \\
\pm \\
2.9 \\
\end{array}$ & $\begin{array}{c}92.3 \\
\pm \\
4.2\end{array}$ & $\begin{array}{c}32.5 \\
\pm \\
3.4\end{array}$ & $\begin{array}{c}76.8 \\
\pm \\
3.4 \\
\end{array}$ & $\begin{array}{c}17.6 \\
\pm \\
1.4 \\
\end{array}$ & $\begin{array}{c}68.7 \\
\pm \\
3.3 \\
\end{array}$ & - & $\begin{array}{c}51.1 \\
\pm \\
2.7 \\
\end{array}$ & - & $\begin{array}{c}30.1 \\
\pm \\
2.9 \\
\end{array}$ & - \\
\hline $\begin{array}{c}\text { сухая масса } \\
\text { проростков, } \\
\text { мг }\end{array}$ & $\begin{array}{c}17.1 \\
\pm \\
0.7\end{array}$ & $\begin{array}{c}15.4 \\
\pm \\
0.6\end{array}$ & $\begin{array}{c}13.4 \\
\pm \\
0.5\end{array}$ & $\begin{array}{c}14.4 \\
\pm \\
0.7\end{array}$ & $\begin{array}{c}13.2 \\
\pm \\
0.7\end{array}$ & $\begin{array}{l}14.1 \\
\pm \\
0.5\end{array}$ & $\begin{array}{c}6.8 \\
\pm \\
0.5\end{array}$ & $\begin{array}{c}12.6 \\
\pm \\
0.5\end{array}$ & $\begin{array}{c}1.6 \\
\pm \\
0.2\end{array}$ & $\begin{array}{c}11.1 \\
\pm \\
0.5\end{array}$ & - & $\begin{array}{c}9.5 \\
\pm \\
0.5\end{array}$ & - & $\begin{array}{c}7.1 \\
\pm \\
0.6\end{array}$ & - \\
\hline
\end{tabular}


В случае с использованием маннита снижение показателей энергии прорастания и всхожести наблюдалось, начиная с концентрации в 4\%, однако минимального значения эти показатели достигали при концентрации маннита в 8\%. Следует отметить, что некоторое количество проклюнувшихся семян у сортов Архат, Башкирская 28 и Омская 36 (табл. 1, 3, 4) наблюдалось и при концентрации маннита в $10 \%$, однако в дальнейшем формирования проростков из них не отмечалось. Таким образом, в качестве сублетальной нужно рассматривать концентрацию маннита в $8 \%$.

При анализе ростовых характеристик проростков было выявлено, что заметное снижение значений таких показателей, как длина органов и их масса начиналось при использовании ПЭГ 6000 в концентрации в 8\% и маннита в концентрации в 6\% и продолжалось с увеличением концентраций селективных агентов, достигая минимальных значений при использовании сублетальных концентраций.

Из приведенных в таблицах результатов видно, что маннит оказывает более агрессивное действие на ростовые показатели, в сравнении с ПЭГ 6000, притом в меньших концентрациях.

Установлено, что наиболее «уязвимая» ростовая характеристика - длина надземной части (колеоптиля или колеоптиля с появившимся из него первым листом).

Данный факт можно объяснить токсическим действием иммитантов засухи на меристематические клетки апекса побега. Цито-гистологический статус апекса побега после воздействия селективных агентов на примере сорта Жница отражен на рис. 2.

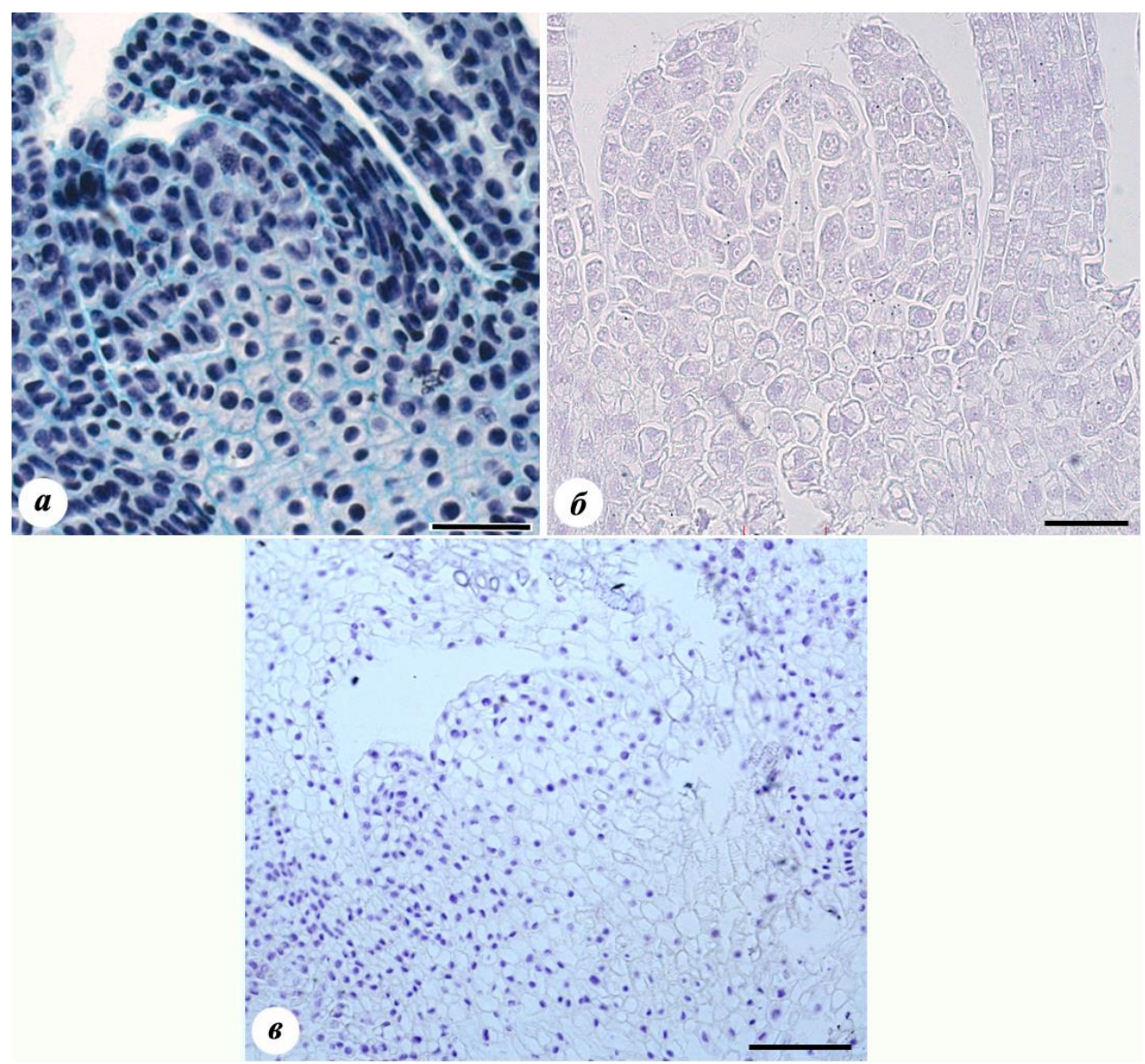

Рис. 2. Цито-гистологический статус клеток апекса побега зародышей пшеницы сорта Жница, пророщенных на дистиллированной воде $(a), 14 \%$ ном растворе ПЭГ 6000 (б) и 8\%-ном растворе маннита (в).

Масштаб - 100 мкм. 
Так, в отличие от контрольного варианта, где клетки апекса побега плотно упакованы, имеют крупные ядра и интенсивно окрашивающуюся цитоплазму (рис. $2 a$ ), клетки апекса побега зародышей, пророщенных на 14\%-ном растворе ПЭГ-6000, подвергаются обезвоживанию и плазмолизу (отделению протопласта от клеточной стенки, рис. 2б), что делает невозможным нормальное функционирование клеток апекса побега. При проращивании семян на 8\%-ном растворе маннита помимо плазмолиза наблюдается также вакуолизация и/или деструкция клеток (рис. 2в).

Наименее изменяющаяся при сублетальных концентрациях селективного агента ростовая характеристика - число корней. Это можно объяснить тем, что сформированный зародыш в зрелой зерновке уже имеет определенное количество корней - первичный и адвентивные корни, прорастающих при не достигающих летального уровня концентрациях селективного агента. Угнетение ростовых параметров при засухе - общеизвестный факт [Терлецкая, 2012; Кудоярова и др., 2013; Веселов и др., 2017]. Так, на примере пшеницы и ячменя показано, что замедление роста листа и первичных корешков в условиях искусственной засухи является важным показателем их чувствительности на стресс [Терлецкая и др., 2011]. При этом считается, что надземная часть более чувствительна к изменению водного потенциала [Munns, 2002], причем эта закономерность характерна для более устойчивых форм [Терлецкая, 2012].

Таким образом, подбор селективного агента и адекватной его концентрации играет важную роль при проведении экспериментов по селекции генотипов на устойчивость к засухе. Так, при низких концентрациях селективного агента устойчивость к стрессу может не проявляться, а слишком высокие концентрации могут быть летальными для растений. В литературе сообщается о достаточно широко варьирующих селективных концентрациях ПЭГ 6000 и маннита, используемых для оценки устойчивости злаков к засухе - от 1-5\% [Тучин, 2000; Шек и др., 2006; Bunnag, Suwanagul, 2017; Marssaro et al., 2017] до 20\% [Терлецкая, 2008; Круглова, 2014] и выше [Аль-Холани, 2010; Tripathy, 2015].

Сообщается, что сублетальные концентрации селективных агентов видоспецифичны [Аль-Холани, 2010], поэтому необходимо подбирать дозы селективных факторов для конкретного вида растений. Поэтому необходимость подбора селективного агента и адекватной его концентрации для каждого конкретного случая не вызывает сомнений.

Сравнительный анализ полученных нами результатов показывает, что ПЭГ 6000 оказывает более мягкое действие по сравнению с маннитом, селективная концентрация которого значительно ниже. Полученные нами данные сходны с данными по использованию тест-систем с ПЭГ для других видов растений [Аль-Холани, 2010].

На основании полученных данных для оценки пшеницы на устойчивость к засухе рекомендуется использовать концентрации ПЭГ-6000 в 12-14\%.

В исследованиях использовали приборную базу Центра коллективного пользования “Агидель” УФИЦ РАН.

Работа выполнена в рамках государственного задания Минобрнауки России № 07500326-19-00 по теме № АААА-А18-118022190099-6. 


\section{СПИСОК ЛИТЕРАТУРЫ}

1. Аль-Холани Х.А. Получение стресс-толерантных растений кукурузы методом клеточной селекции: Автореф. дис. ... канд. биол. наук. М.: Институт физиологии растений им. К.А. Тимирязева РАН, 2010. 24 с.

2. Веселов Д.С., Кудоярова Г.Р., Кудрякова Н.В., Кузнецов В.В. Роль цитокининов в стресс-устойчивости растений // Физиол. раст. 2017. Т. 64. № 1. С. 19-32. DOI: $\underline{10.7868 / \mathrm{S} 001533031701016 \mathrm{X}}$

3. ГОСТ 12038-84. Семена сельскохозяйственных культур. Методы определения всхожести. - URL http://docs.cntd.ru/document/gost-12038-84

4. Гусева Н.Н., Афанасенко О.С., Высоцкая Р.И., Мироненко Н.В., Плащев В.М., Белявский Ю.В. Биотехнология и проблемы селекции растений на устойчивость // Защита растений. 1990. № 8. С. 3-5.

5. Дьячук Т.И., С.В. Тучин, Столяров С.В., Итальянская Ю.В., Сафронова Н.Ф., Медведева Л.П., Блюднева Е.А. Биотехнологические методы в селекции пшеницы, ячменя и тритикале в НИИСХ Юго-Востока // Стратегия адаптивной селекции полевых культур в связи с глобальным изменением климата: Сборник науч. трудов по материалам науч. практ. конф. Саратов, 2004. С. 237-278.

6. Зыбалов В.С. Засуха и меры борьбы с ней на Южном Урале // Вестник Челябинского государственного агроинженерного университета. 2013. Т. 63. С. 101-106.

7. Круглова Н.Н. Выявление автономности зародыша пшеницы как этап разработки экспресс-диагностической биотехнологии получения засухоустойчивых образцов // Пермский аграрный вестник. 2014. № 1 (5). С. 38-43.

8. Круглова Н.Н., Егорова О.В., Сельдимирова О.А., Зайцев Д.Ю., Зинатуллина А.Е. Световой микроскоп как инструмент в биотехнологии растений. Уфа: Гилем, Башк. энцикл., 2013. 128 с.

9. Круглова Н.Н., Сельдимирова О.А., Зинатуллина А.Е. Каллус in vitro как модельная система для исследования стрессоустойчивости растений к абиотическим факторам (на примере злаков) // Успехи современной биологии. 2018. Т. 138. № 3. С. 283-293. DOI: $\underline{10.7868 / \mathrm{S} 0042132418030067}$

10. Кудоярова Г.Р., Холодова В.П., Веселов Д.С. Современное состояние проблемы водного баланса растений при дефиците воды // Физиология растений. 2013. Т. 60. № 2. С. 155165. DOI: $10.7868 / \mathrm{S} 0015330313020140$

11. Никитина Е.Д., Хлебова Л.П., Соколова Г.Г., Ерещенко О.В. Создание стрессоустойчивого материала яровой мягкой пшеницы с использованием клеточной селекции in vitro // Известия Алтайского государственного университета. 2013. № 3. С. 95-98. DOI: 10.14258/izvasu(2013)3.2-20

12. Россеев В.М., Белан И.А., Россеева Л.П. Тестирование in vitro яровой мягкой пшеницы на засухоустойчивость // Вестник Алтайского государственного аграрного университета. 2011. № 2 (76). С. 32-34. 
13. Россеев В.М., Белан И.А., Россеева Л.П. Использование метода in vitro в селекции пшеницы мягкой яровой // Вестник Алтайского государственного аграрного университета. 2016. № 2 (136). С. 5-9.

14. Терлецкая Н.В. Диагностика устойчивости мягкой пшеницы к засухе и солевому стрессу, моделируемым in vivo и in vitro // Биотехнология. Теория и практика. 2008. № 4. C. 64-70.

15. Терлецкая Н.В. Неспецифические реакции зерновых злаков на абиотические стрессы in vivo и in vitro. Алматы: ИП Н.А. Волкова, 2012. 208 с.

16. Терлецкая Н.В., Хайленко Н.А., Искакова А.Б. Особенности реакции проростков аллоплазматических линий мягкой пшеницы на действие осмотического и солевого стресса // Вестник Самарского гос. ун-та. Естественнонаучн. серия. 2011. № 2(3). C. 244-249.

17. Тучин С.В. Моделирование стресса обезвоживания в культуре изолированных тканей пшеницы и его биологические последствия: Автореф. дис. ... д-ра биол. наук. М.: Всероссийский научно-исследовательский институт сельскохозяйственной биотехнологии РАСХН, 2000. 46 c.

18. Шек Г.О., Хапилина О.Н., Турганбаева А.К., Сейтбатталова А.И., Оразалиева Ж.Б., Созинова Л.Ф., Саданов А.К. Выбор оптимальных схем клеточной селекции яровой мягкой пшеницы на устойчивость к стрессовым факторам среды // Биотехнология. Теория и практика. 2006. № 4. С. 92-95.

19. Bunnag S., Suwanagul A. Improvement of drought tolerance in Thai rice cultivar RD6 through somaclonal variation // Songklanakarin J. Sci. Technol. 2017. V. 39. № 6. P. 723-729.

20. Marssaro A.L., Morais-Lino L.-S., Cruz J.L., da Silva Ledo C.A., dos Santos-Serejo J.A. Simulation of in vitro water deficit for selecting drought-tolerant banana genotypes // Pesq. Agropec. Bras. 2017. V. 52. № 12. P. 1301-1304. DOI: 10.1590/s0100-204x2017001200021

21. Munns R. Comparative physiology of salt and water stress // Plant Cell Environ. 2002. V. 25. № 2. P. 239-250. DOI: 10.1046/j.0016-8025.2001.00808.x

22. Tripathy S.K. In Vitro Screening of Callus Cultures and Regenerants for Drought Tolerance in Upland Rice // Res. J. Biotech. 2015. V. 10. № 6. P. 23-28. 